\section{Migração internacional, saúde e trabalho: uma análise sobre os haitianos em Mato Grosso, Brasil}

International migration, health, and work: an analysis of Haitians in Mato Grosso State, Brazil

Migración internacional, salud y trabajo: un análisis sobre los haitianos en Mato Grosso, Brasil

\section{Resumo}

Este artigo aborda as relações entre imigração, saúde e trabalho e tem o objetivo de caracterizar a população de imigrantes haitianos em Cuiabá e Várzea Grande, Mato Grosso, Brasil, destacando suas condições de trabalho. Trata-se de um estudo exploratório com base em dados primários, coletados por meio de um inquérito aplicado à população haitiana em Cuiabá em 2014-2015. Foram entrevistados 452 haitianos residentes em Cuiabá e Várzea Grande (sendo 373 homens e 79 mulheres), e os resultados indicaram uma precária situação social dos imigrantes haitianos no Estado de Mato Grosso, marcada por elevada proporção de desemprego. Dos imigrantes entrevistados, 52,7\% estavam trabalhando e 26,5\% relataram carga horária semanal superior a 48 horas. Os dois principais grupos de ocupações exercidos por imigrantes haitianos em Cuiabá foram a construção civil e o setor de serviços e a maioria dos trabalhadores exerciam funções aquém da sua formação e profissões exercidas no Haiti. Os principais riscos percebidos nesses dois setores foram físicos $(53,2 \%$ e 63,4\%, respectivamente) e de acidentes $(23,4 \%$ e $17,1 \%$, respectivamente) e também foram relatadas manifestações de sofrimento físico e psicossocial. Essa pesquisa aponta para a precária condição social, econômica e laboral da população haitiana na capital mato-grossense.

Emigração e Imigração; Saúde do Trabalhador; Riscos Ocupacionais; Estresse Psicológico
Luís Henrique da Costa Leão 1

Ana Paula Muraro 1

Cássia Carraco Palos 1

Maria Angela C. Martins 1

Fabiano Tonaco Borges 2

doi: 10.1590/0102-311X00181816

\section{Correspondência}

L. H. C. Leão

Instituto de Saúde Coletiva, Universidade Federal de Mato

Grosso.

Av. Fernando Corrêa da Costa 2367, Cuiabá,

MT 78060-900, Brasil.

luis_leao@hotmail.com

1 Instituto de Saúde Coletiva, Universidade Federal de Mato Grosso, Cuiabá, Brasil.

2 Instituto de Saúde Coletiva, Universidade Federal Fluminense, Niterói, Brasil. 


\section{Introdução}

O Brasil tornou-se destino da diáspora haitiana a partir de 2010, e já são mais de 39 mil haitianos no país 1,2. Os destinos prioritários têm sido os estados das regiões Sul e Sudeste, no entanto o Estado de Mato Grosso passou a ser destino ou passagem de imigrantes haitianos a partir de 2012. Em 2014, o estado ficou em quinto lugar, totalizando 910 haitianos com vínculo formal de trabalho no cenário de 23.017 registrados em todo país 2. Porém, não existem informações oficiais precisas sobre esse fluxo migratório ou sobre as condições de vida e trabalho dessa população na sociedade mato-grossense. $\mathrm{O}$ objetivo desse artigo foi caracterizar a população de imigrantes haitianos em Cuiabá e Várzea Grande, Estado de Mato Grosso, destacando suas condições de trabalho.

\section{Método}

Trata-se de uma pesquisa exploratória e quantitativa com dados obtidos por meio de um inquérito aplicado à população haitiana nas cidades de Cuiabá e Várzea Grande. O questionário foi composto de questões fechadas e abertas que abrangiam informações demográficas, socioeconômicas, domínio de idiomas e relativas ao trabalho que cada entrevistado exercia no momento da pesquisa, incluindo informações sobre exposição a riscos ocupacionais, caracterização das condições/relações de trabalho e manifestações de sofrimento. Delineou-se uma amostra probabilística, proporcional por sexo, adotando-se para o cálculo da amostra os procedimentos de Lwanga \& Lemeshow ${ }^{3}$.

Foi considerado para o cálculo amostral o número de imigrantes haitianos acolhidos pelo Centro de Pastoral para Migrantes (CPM) de Cuiabá, no período de 2012 a 2014 ( $\mathrm{n}=1.059,16 \%$ do sexo feminino), utilizou-se a proporção máxima sob o nível de $95 \%$ de confiança $(\mathrm{p}=0,50)$ e um erro tolerável de 4\%, chegando ao número 383 indivíduos. Considerando-se as possíveis perdas, acrescentou-se ainda 15\% (57 indivíduos) à amostra, obtendo-se o total de 440 indivíduos para compor a população do estudo (370 homens e 70 mulheres).

A coleta dos dados ocorreu entre dezembro de 2014 e fevereiro de 2015. As entrevistas foram realizadas por entrevistadores bilíngues (Crioulo/Português). Os participantes foram contatados por telefone ou pessoalmente e convidados a participar da pesquisa, sendo os contatos telefônicos e endereços obtidos no CPM. Os dados coletados por meio do inquérito passaram por dupla digitação e validação por meio do software Epi Info 7 (Centers for Disease Control and Prevention, Atlanta, Estados Unidos). A análise de dados foi realizada por meio do software SPSS, versão 17 (SPSS Inc., Chicago, Estados Unidos). Foi utilizado o teste do qui-quadrado para testar as diferenças entre os grupos, adotando-se a significância ao nível de 5\%. A pesquisa atendeu à legislação concernente à pesquisa com seres humanos, tendo sido aprovado por comitê de ética (no 29120414.0.0000.5541).

\section{Resultados}

Foram entrevistados 452 haitianos residentes em Cuiabá e Várzea Grande (sendo 373 homens e 79 mulheres). A maioria tinha menos de 35 anos de idade, era casada ou em união estável, e menor proporção de mulheres declarou dominar três ou mais idiomas e ter renda maior que um salário mínimo (Tabela 1). Uma importante parcela dos imigrantes relatou não ter obtido nenhuma renda (30,1\%), o que pode estar relacionado ao fato de $10,9 \%(n=49)$ dos entrevistados terem chegado ao Brasil há menos de 30 dias da entrevista; portanto, ainda estavam morando no CPM e sem emprego. Entre os homens que relataram não possuir renda, muitos afirmaram estar vivendo de reservas econômicas feitas quando estavam trabalhando ou com a ajuda de amigos e/ou familiares. Além disso, 71\% relataram ter dívidas financeiras relacionadas à imigração (dados não apresentados em tabela).

Dos imigrantes entrevistados, 52,7\% estavam empregados. Grande parte tinha entre 3 e 6 meses no trabalho atual (38,7\%) e relatou carga horária semanal maior que 48 horas (26,5\%). Observou-se que a maioria dos trabalhadores tinha vínculo formal, porém maior proporção de mulheres tinha vínculo por contrato temporário e não possuía experiência anterior na função (61,9\%). Metade relatou ter tido treinamento de segurança do trabalho e $43 \%$ algum tipo de capacitação (Tabela 2). 
Tabela 1

Características demográficas e socioeconômicas, segundo sexo, de imigrantes haitianos residentes em Cuiabá, Mato Grosso, Brasil, 2015.

\begin{tabular}{|c|c|c|c|c|c|c|c|}
\hline \multirow[t]{2}{*}{ Características } & \multicolumn{2}{|c|}{$\begin{array}{c}\text { Total } \\
(n=452)\end{array}$} & \multicolumn{2}{|c|}{$\begin{array}{c}\text { Masculino } \\
(n=373)\end{array}$} & \multicolumn{2}{|c|}{$\begin{array}{c}\text { Feminino } \\
(n=79)\end{array}$} & \multirow[t]{2}{*}{ Valor de $p$ * } \\
\hline & $\mathbf{n}$ & $\%$ & $\mathbf{n}$ & $\%$ & $\mathbf{n}$ & $\%$ & \\
\hline Faixa etária (anos) ** & & & & & & & 0,88 \\
\hline 25 ou menos & 71 & 15,7 & 61 & 16,4 & 10 & 12,8 & \\
\hline $26-35$ & 200 & 44,3 & 165 & 44,2 & 35 & 44,9 & \\
\hline $36-45$ & 141 & 31,3 & 115 & 30,8 & 26 & 33,3 & \\
\hline Mais de 45 & 39 & 8,6 & 32 & 8,6 & 7 & 9,0 & \\
\hline Escolaridade ** & & & & & & & - \\
\hline Até o Ensino Fundamental completo & 223 & 50,8 & 178 & 48,9 & 45 & 60,0 & \\
\hline Ensino Médio incompleto & 164 & 37,4 & 136 & 37,4 & 28 & 37,3 & \\
\hline Ensino Médio completo ou mais & 52 & 11,8 & 50 & 13,7 & 2 & 2,7 & \\
\hline Renda no último mês (Reais) ** & & & & & & & $<0,01$ \\
\hline Nenhuma & 136 & 30,1 & 104 & 29,5 & 32 & 41,6 & \\
\hline$\leq 724,00$ & 71 & 15,7 & 51 & 14,4 & 20 & 26,0 & \\
\hline$\geq 725,00$ & 245 & 56,2 & 218 & 58,4 & 27 & 34,2 & \\
\hline Estado civil *** & & & & & & & 0,64 \\
\hline Casado ou em união estável & 302 & 66,8 & 251 & 67,3 & 51 & 64,6 & \\
\hline Solteiro (ou separado ou viúvo) & 150 & 33,2 & 122 & 32,7 & 28 & 35,4 & \\
\hline Número de filhos & & & & & & & 0,62 \\
\hline Sem filhos & 73 & 16,2 & 60 & 16,1 & 13 & 16,5 & \\
\hline $1-2-$ & 216 & 47,8 & 174 & 46,6 & 42 & 53,2 & \\
\hline $3-5$ & 130 & 28,8 & 112 & 30,0 & 18 & 22,8 & \\
\hline Mais de 5 & 33 & 7,3 & 27 & 7,2 & 6 & 7,6 & \\
\hline Entende Português & & & & & & & 0,07 \\
\hline Muito pouco & 210 & 47,9 & 166 & 45,5 & 44 & 60,3 & \\
\hline Pouco & 80 & 18,3 & 70 & 19,2 & 10 & 13,7 & \\
\hline Razoavelmente, bem ou muito bem & 148 & 33,8 & 129 & 35,3 & 19 & 26,0 & \\
\hline Quantos idiomas fala e compreende & & & & & & & $<0,01$ \\
\hline Apenas Crioulo & 88 & 19,5 & 59 & 15,8 & 29 & 36,7 & \\
\hline Crioulo e mais outro idioma & 146 & 32,3 & 119 & 31,9 & 27 & 34,2 & \\
\hline Crioulo e outros dois ou mais idiomas & 218 & 48,2 & 195 & 52,3 & 23 & 29,1 & \\
\hline Tempo de residência no Brasil ** & & & & & & & 0,58 \\
\hline Menos de 30 dias & 49 & 10,9 & 43 & 11,6 & 6 & 7,6 & \\
\hline Entre 1 mês e 1 ano & 177 & 39,3 & 145 & 39,1 & 32 & 40,5 & \\
\hline 1 ano ou mais & 224 & 49,8 & 183 & 49,3 & 41 & 51,9 & \\
\hline Trabalho atual no Brasil & & & & & & & 0,73 \\
\hline Sim & 238 & 52,7 & 195 & 52,3 & 43 & 54,4 & \\
\hline Não & 214 & 47,3 & 183 & 47,7 & 36 & 45,6 & \\
\hline
\end{tabular}

* Valor de $p$ do teste do qui-quadrado;

** Informações faltantes: idade (1 entrevistado), escolaridade (13 indivíduos), renda no último mês (22 indivíduos que não quiseram informar) e tempo de residência no Brasil (2 indivíduos);

*** Apenas 6 relataram estar separados (ou divorciados) e 3 relataram ser viúvos.

A ocupação no Haiti mais frequentemente relatada foi a de trabalhador em produção agrícola e apenas 10 entrevistados relataram estar desempregados. Entre os homens, 25,2\% trabalhavam na agricultura, 17,4\% eram estudantes e a profissão de pedreiro foi a terceira mais citada (12,1\%). Entre as mulheres, a maioria (60,8\%) relatou ser comerciante. Já no Brasil, a maioria dos homens que estava 


\section{Tabela 2}

Características relativas ao trabalho, segundo sexo, de imigrantes haitianos residentes em Cuiabá, Mato Grosso, Brasil, 2015.

\begin{tabular}{|c|c|c|c|c|c|c|c|}
\hline \multirow[t]{2}{*}{ Características } & \multicolumn{2}{|c|}{$\begin{array}{c}\text { Total } \\
(n=238)\end{array}$} & \multicolumn{2}{|c|}{$\begin{array}{c}\text { Masculino } \\
(n=195)\end{array}$} & \multicolumn{2}{|c|}{$\begin{array}{c}\text { Feminino } \\
(n=43)\end{array}$} & \multirow[t]{2}{*}{ Valor de $p$ * } \\
\hline & $\mathbf{n}$ & $\%$ & $\mathbf{n}$ & $\%$ & $\mathbf{n}$ & $\%$ & \\
\hline Tipo de vínculo & & & & & & & - \\
\hline Carteira de trabalho assinada & 199 & 83,6 & 170 & 87,2 & 29 & 67,4 & \\
\hline Contrato & 19 & 8,0 & 6 & 3,1 & 13 & 30,2 & \\
\hline Informal & 20 & 8,4 & 19 & 9,7 & 1 & 2,3 & \\
\hline Tempo que está no emprego atual & & & & & & & 0,25 \\
\hline Menos de 1 mês & 20 & 8,4 & 16 & 8,2 & 4 & 9,3 & \\
\hline$\geq 1$ mês e $<3$ meses & 31 & 13,0 & 26 & 13,3 & 5 & 11,6 & \\
\hline$\geq 3$ meses e $<6$ meses & 92 & 38,7 & 81 & 41,5 & 11 & 25,6 & \\
\hline$\geq 6$ meses $\mathrm{e} \leq 12$ meses & 62 & 26,1 & 46 & 23,6 & 16 & 37,2 & \\
\hline Mais de um ano & 33 & 13,9 & 26 & 13,3 & 7 & 16,3 & \\
\hline Carga horária semanal de trabalho (horas) & & & & & & & 0,10 \\
\hline$\leq 44$ & 66 & 27,7 & 58 & 29,7 & 8 & 18,6 & \\
\hline$>44$ e $\leq 48$ & 109 & 45,8 & 83 & 42,6 & 26 & 60,5 & \\
\hline$>48$ & 63 & 26,5 & 54 & 27,7 & 9 & 20,9 & \\
\hline Experiência prévia na ocupação que exerce ** & & & & & & & $<0,01$ \\
\hline Sim & 139 & 58,4 & 122 & 62,6 & 17 & 39,5 & \\
\hline Não & 99 & 41,6 & 73 & 37,4 & 26 & 60,5 & \\
\hline Capacitação para o trabalho que exerce & & & & & & & 0,16 \\
\hline Sim & 101 & 42,4 & 87 & 44,6 & 14 & 32,6 & \\
\hline Não & 137 & 57,6 & 108 & 55,4 & 29 & 67,4 & \\
\hline Treinamento de segurança do trabalho & & & & & & & - \\
\hline $\operatorname{Sim}$ & 124 & 52,3 & 107 & 55,2 & 17 & 39,5 & \\
\hline Não & 106 & 44,7 & 81 & 41,8 & 25 & 58,1 & \\
\hline Não sei & 7 & 3,0 & 6 & 3,1 & 1 & 2,4 & \\
\hline Discriminação no trabalho & & & & & & & 0,56 \\
\hline Sim & 53 & 22,3 & 42 & 21,5 & 11 & 25,6 & \\
\hline Não & 185 & 77,7 & 153 & 78,5 & 32 & 74,4 & \\
\hline
\end{tabular}

* Valor de p do teste do qui-quadrado;

** Informação faltante: experiência anterior (3 entrevistados).

trabalhando ocupava postos de ajudante de pedreiro (48,7\%) e mais da metade das mulheres $(53,5 \%)$ compunha o quadro de trabalhadoras de serviços de limpeza (dados não apresentados em tabela).

Os dois principais grupos de ocupações exercidos por imigrantes haitianos em Cuiabá foram a construção civil e o setor de serviços. Neles, os principais riscos percebidos foram físicos $(53,2 \%$ e $63,4 \%$, respectivamente) e de acidentes (23,4\% e 17,1\%, respectivamente). Verificou-se também o relato de agrupamentos de riscos, ou seja, trabalhadores que relataram perceber mais de um risco, como físicos e químicos ou físicos e de acidentes. Menos da metade dos entrevistados relatou capacitação prévia para a tarefa que realizava. Além disso, 62,5\% dos trabalhadores da construção civil e 55,2\% de setor serviços relataram já ter participado de algum tipo de treinamento em segurança do trabalho (dados não apresentados em tabela).

Entre os que estavam trabalhando, 90 referiram queixas sobre o que mais incomodava na execução das atividades. Nesse quesito, surgiram elementos referentes às dificuldades de lidar com os patrões e gestores, não trabalhar na função adequada e à gestão e organização do trabalho, com destaque para a falta de reconhecimento e valorização da empresa que "não gosta de estrangeiro". O tema que mais 
sobressaiu foi a remuneração, pois 24 deles manifestaram insatisfação quanto aos salários que são "muito baixos". Além disso, houve relatos de atrasos e até falta de pagamento.

Outro grupo de queixas foi relativo às manifestações de sofrimento físico e psicossocial. Foram referidas dores na coluna, cabeça, barriga ou corpo inteiro, além de esforço intenso, cansaço, insegurança na execução de atividades etc. Foram relatados igualmente intimidação, humilhação, desrespeito e saudade da família, conforme a expressão de um trabalhador imigrante: "todo momento fico pensando em minha família”.

\section{Discussão}

Os resultados da pesquisa mostram uma precária situação social dos imigrantes haitianos no Estado de Mato Grosso, marcada por elevada proporção de desemprego. Tendo em conta a centralidade do trabalho para os fenômenos migratórios, e que muitos haitianos vieram ao Brasil na expectativa de conseguir trabalho 5 , essa situação pode levar à percepção da piora na saúde e distúrbios mentais, conforme vem sendo mostrado em pesquisas de diversos contextos mundiais 6,7 .

Quanto aos que estavam trabalhando, chama a atenção a extensa jornada de trabalho a que grande parte dos entrevistados estava submetida. O relato de dores no corpo e cansaço pode estar relacionado à carga horária, além da exigência física e riscos percebidos, que interatuam com o corpo dos trabalhadores e geram perda das capacidades corporais e psíquicas ${ }^{8}$. Pesquisas apontam problemas de saúde mental em trabalhadores migrantes, como casos de depressão ocasionados pela "solidão aliada à longa e exaustiva jornada de trabalho", silêncio sobre o adoecer e o medo de perder o emprego e não conseguir se manter longe de casa 6,7,9.

Os dois principais setores em que estão inseridos os haitianos - construção civil e serviços - estão entre os principais ramos de geração tanto de empregos quanto de acidentes e doenças ocupacionais no Brasil. Em 2011, o setor de serviços teve o maior índice de acidentes (341 mil notificações de acidentes de trabalho) e a construção civil apresentou o maior aumento do registro desse índice com 59.808 acidentes de trabalho computados 4.

Outro ponto importante é a discrepância entre a formação e as profissões exercidas no Haiti e no Mato Grosso. Existem haitianos qualificados exercendo funções que exigem pouca qualificação, devido à falta de revalidação de diplomas.

Apesar de não haver diferenças entre as proporções de homens e mulheres que trabalhavam em Cuiabá no momento da pesquisa, as mulheres possuíam menor remuneração salarial, menos treinamento em segurança do trabalho e não tinham experiência nas atividades que exerciam. Tais dados reforçam a aparente maior vulnerabilidade das mulheres, ligada à divisão sexual do trabalho 10 .

\section{Considerações finais}

A pesquisa apontou a precária condição social, econômica e laboral da população haitiana na capital mato-grossense. A inserção dos imigrantes haitianos esteve associada a setores de produção que, historicamente, submetem trabalhadores a condições ruins de trabalho, com repercussões na saúde. A caracterização desse novo grupo de trabalhadores vulneráveis no contexto das relações saúde-trabalho brasileiras desperta para o desafio da saúde pública e demais setores do Estado para conhecer e criar estratégias para melhorar as condições de trabalho dos haitianos.

Estudos futuros podem ser realizados a fim de identificar expectativas, frustrações e anseios desses trabalhadores de modo aprofundado, compreender as vivências de sofrimentos e resistências coletivas, bem como as redes de apoio social. Além disso, faz-se necessário levantamento de agravos e danos à saúde de trabalhadores imigrantes delimitado por ramo produtivo conforme este estudo identificou. 


\section{Colaboradores}

L. H. C. Leão, A. P. Muraro e F. T. Borges participaram da concepção do manuscrito, análise e interpretação dos dados, redação do artigo e revisão crítica relevante do conteúdo intelectual; são responsáveis por todos os aspectos do trabalho na garantia da exatidão e integridade de qualquer parte da obra. C. C. Palos e M. A. C. Martins participaram da interpretação dos dados e redação do artigo. Todos os autores aprovaram a versão a ser publicada.

\section{Agradecimentos}

Os autores são extremamente gratos à Coordenação do Centro de Pastoral para Migrantes de Cuiabá, às pessoas que aceitaram participar do inquérito, aos entrevistadores bilíngues e aos alunos de graduação e pós-graduação envolvidos na coleta de dados. Os autores agradecem também à Fundação de Amparo à Pesquisa do Estado de Mato Grosso (FAPEMAT; processo 155709/2014) e ao Conselho Nacional de Desenvolvimento Científico e Tecnológico (CNPq; processo 445842/2014-7) pelo financiamento da pesquisa.

\section{Referências}

1. Agência da ONU para Refugiados. Refúgio no Brasil: uma análise estatística (janeiro de 2010 a outubro de 2014). http://www.acnur.org/t3/fileadmin/ Documentos/portugues/Estatisticas/Refugio no_Brasil_2010_2014.pdf?view=1 (acessado em Jan/2016).

2. Cavalcanti L. Imigração e mercado de trabalho no Brasil: características e tendências. Cadernos Obmigra - Revista Migrações Intrenacionais 2015; 1:35-47.

3. Lwanga SK, Lemeshow S. Sample size determination in health studies: a practical manual. Geneva: World Health Organization; 1991.

4. Revista Proteção. Estatísticas de acidentes no Brasil. http://migre.me/qINAB (acessado em Nov/2015).

5. Cotinguiba GC. Imigração haitiana para o Brasil - a relação entre trabalho e processos migratórios [Dissertação de Mestrado]. Porto Velho: Universidade Federal de Rondônia; 2014.
6. Benach J, Muntaner C, Chung H, Benavides FG Immigration, employment relations, and health: developing a research agenda. Am J Ind Med 2010; 53:338-43.

7. Ahonen EQ, Benavides FG, Benach J. Immigrant populations, work and health: a systematic literature review. Scand J Work Environ Health 2007; 33:96-104.

8. Laurell AC, Noriega M. Processo de produção e saúde: trabalho e desgaste operário. São Paulo: Editora Hucitec; 1989.

9. Menezes MA, Marcelo SS. "A cana judia de nós!" Impactos da migração e da atividade de cortar cana sobre a saúde dos trabalhadores migrantes nordestinos. In: VIII Congresso Latino-americano de Sociologia Rural. Porto de Galinhas: Asociación Latinoamericana de Sociología Rural; 2010.

10. Hirata H, Kergoat D. Novas configurações da divisão sexual do trabalho. Cad Pesqui 2007; 37:595-609. 


\section{Abstract}

This article addresses the relations between immigration, health, and work in Haitian immigrants in Cuiabá and Várzea Grande, Mato Grosso State, Brazil, emphasizing their work conditions. This was an exploratory study based on primary data collected through a survey of the Haitian population in Cuiabá in 2014-2015. A total of 452 Haitians were interviewed, living in Cuiabá and Várzea Grande (373 men and 79 women), and the findings point to the precarious social situation of Haitian immigrants in Mato Grosso State, marked by high unemployment. Of the immigrants interviewed, $52.7 \%$ were currently working and $26.5 \%$ reported a workweek greater than 48 hours. The two main occupations for Haitian immigrants in Cuiabá were construction and services, and most were working below their original level of training, skills sets, and job experience in Haiti. The main risks identified in these two sectors were physical (53.2\% and $63.4 \%$, respectively) and accidents $(23.4 \%$ and $17.1 \%$, respectively), in addition to reports of physical and psychosocial distress. The study points to the precarious social, econom$i c$, and labor conditions of the Haitian population in the capital of Mato Grosso.

Emigration and Immigration; Occupational Health; Occupational Risks;

Psychological Stress

\section{Resumen}

Este artículo aborda las relaciones entre inmigración, salud y trabajo y tiene el objetivo de caracterizar la población de inmigrantes haitianos en Cuiabá y Várzea Grande, Mato Grosso, Brasil, destacando sus condiciones de trabajo. Se trata de un estudio exploratorio, basado en datos primarios, recogidos mediante una encuesta aplicada a la población haitiana en Cuiabá en 2014/2015. Se entrevistó a 452 haitianos, residentes en Cuiabá y Várzea Grande (siendo 373 hombres y $79 \mathrm{mu}$ jeres), $y$ los resultados indicaron una precaria situación social de los inmigrantes haitianos en el estado de Mato Grosso, marcada por la elevada proporción de desempleo. Dos inmigrantes entrevistados, 52,7\% estaban trabajando y un 26,5\% informaron de una carga horaria semanal superior a las 48 horas. Los dos principales grupos de ocupaciones, ejercidos por inmigrantes haitianos en Cuiabá, fueron a la construcción civil y el sector de servicios. Además, la mayoría de los trabajadores ejercian funciones más allá de su formación y profesiones ejercidas en Haití. Los principales riesgos percibidos en esos dos sectores fueron físicos (53,2\% e 63,4\%, respectivamente) y de accidentes (23,4\% y 17,1\%, respectivamente) y también fueron relatadas manifestaciones de sufrimiento físico y psicosocial. Esta investigación apunta a la precaria condición social, económica y laboral de la población haitiana en la capital mato-grossense.

Emigración e Inmigración; Salud Laboral;

Riesgos Laborales; Estrés Psicológico
Recebido em 19/Out/2016

Versão final reapresentada em 21/Abr/2017

Aprovado em 12/Mai/2017 